\title{
Sperm competition and sperm cooperation: the potential role of diploid and haploid expression
}

\author{
Simone Immler \\ Department of Animal and Plant Sciences, University of Sheffield, Western Bank, Sheffield S10 2TN, UK \\ Correspondence should be addressed to S Immler; Email: s.immler@sheffield.ac.uk
}

\begin{abstract}
Sperm competition is a powerful selective force driving the evolution of sperm shape and function. Recent findings suggest that sperm cooperation is a potential evolutionary response to sperm competition. Sperm cooperation may enhance the performance of the ejaculate increasing a male's chance to outcompete rival males in competition for fertilisation. Whether and how sperm cooperation may evolve is the focal point of this review. The relative importance of haploid and diploid gene expression for the evolution of sperm cooperation and the potential conflict of interest between (i) haploid sperm and diploid male and (ii) among sibling sperm, since sibling sperm only share an average of $\mathbf{5 0} \%$ of their genes in a diploid organism, are discussed. Furthermore, sperm cooperation is defined and the literature for empirical evidence of sperm cooperation is reviewed in light of the author's definitions.

Reproduction (2008) 135 275-283
\end{abstract}

\section{Sperm competition}

Sperm competition is defined as the competition between sperm of two or more different males for the fertilisation of a set of ova (Parker 1970, 1998). Based on this idea, researchers have investigated and confirmed the relationship between risk/intensity of sperm competition and ejaculate traits such as sperm number, sperm size and sperm motility both in theory (see Parker 1998 for a review) and empirically in a wide range of taxa (see Birkhead \& Møller 1998, Snook 2005 for reviews). However, it has become evident that the outcome of sperm competition is not entirely determined by male traits but may be strongly influenced by the female through cryptic female choice (Eberhard 1996, Birkhead \& Pizzari 2002). Yet, despite the active investigation of the relationship between postcopulatory sexual selection (i.e. sperm competition and cryptic female choice) and the evolution of sperm design and function, we still know very little about the true function of the majority of sperm traits.

One possible reason for the gaps in our understanding of the function of certain sperm traits is that most theoretical and empirical approaches to sperm competition assume that sperm of one male act as a functional entity, similar to somatic tissue cells forming an organ. However, the fundamental difference between somatic cells and sperm is that somatic cells are genetically identical copies of each other resulting from mitosis, whereas sperm are genetically independent haploid units resulting from the processes of meiosis. The genetic variation among sperm of one male (hereafter, referred to as sibling sperm) may have important consequences for the evolution of sperm shape and function, three of which are: (i) sibling sperm are not necessarily all phenotypically identical if the haploid set of genes has any influence on the evolution of sperm shape and function (Joseph \& Kirkpatrick 2004). (ii) Genetic differences among sibling sperm imply that sperm of one male compete against each other for the fertilisation of eggs (Parker \& Begon 1993, Haig \& Bergstrom 1995). (iii) Finally, haploid and diploid gene expression may have diverging effects on the evolution of sperm shape and function, as the diploid male's interests are not necessarily congruent with the haploid sperm's interests resulting in a potential conflict of interest between male and sperm (Reiss 1987, Parker \& Begon 1993, Haig \& Bergstrom 1995). Empirical evidence for the relative importance of diploid and haploid expression for sperm design and function is increasing (Joseph \& Kirkpatrick 2004), and it is clear that haploid gene expression and differential shape and function among sibling sperm are of importance in the context of postcopulatory sexual selection: from the male's point of view, any of its sperm may fertilise the egg as long as it is its own, whereas sibling sperm will compete among each other (Parker \& Begon 1993).

The three arguments listed above are of particular relevance in situations referred to as 'sperm cooperation', where sperm appear to 'cooperate' to increase a male's fertilisation success (e.g. Sivinski 1984, Hayashi 1998, Moore \& Moore 2002, Moore et al. 2002). The likelihood that 'sperm cooperation' will evolve is affected by the fact that sperm are genetically independent units and different both from each other and from the male that produces 
them. In this review, the potential for 'sperm cooperation' to evolve in response to post-copulatory sexual selection is discussed. First, 'sperm cooperation' is defined and then the potential conflict of interest between haploid and diploid gene sets is discussed. Finally, the literature for empirical evidence of sperm cooperation in light of the definitions in earlier sections is reviewed and the potential costs and benefits of sperm cooperation are discussed.

\section{Sperm cooperation}

Sperm cooperation can be defined as the partitioning of function and/or the mutual interaction between sperm of one male (i.e. sibling sperm) to increase a male's fertilisation success. The partitioning of function among sibling sperm entails four non-exclusive scenarios which lead to fundamentally different outcomes: (i) different tasks may be randomly distributed among sibling sperm and every sperm may play any of the roles or (ii) sibling sperm differentiate into groups with very specific functions. In the first scenario, we would expect sibling sperm to be phenotypically almost identical and with some variation of an optimal design, whereas in the second scenario, differentiation in shape as an adaptation to differentiation in function is likely. Furthermore, sperm cooperation may either imply (iii) the direct interaction between sperm such as sperm grouping (i.e. the formation of pairs or groups between sibling sperm by physical attachment) which results in a better performance of the group as a whole compared with individual sperm or (iv) the indirect interaction between sibling sperm where some sperm may function as 'helpers' for a certain subpopulation of sibling sperm to ensure that the latter reach the site of fertilisation.

The potential for sperm cooperation to evolve depends on the relative importance of diploid and haploid gene expression. If we exclude the potential influence of the male for now, and assume that haploid gene expression is unlimited, sperm cooperation may evolve with the same likelihood as the cooperation between full siblings (Hamilton 1964). The reason for this is that sibling sperm share $50 \%$ of their genes, which is the same relationship as between full siblings and therefore, sperm cooperation will occur if the benefits outweigh the costs (Hamilton 1964). However, the situation becomes more complex when the male is included in the scenario, as two parties are involved, and costs and benefits to both of them have to be evaluated. It will depend on the balance between costs and benefits to the haploid sperm on one side and the diploid male on the other side. It has to be pointed out that sperm share $100 \%$ of their genes with the male (but the male shares only $50 \%$ of its genes with the sperm due to its diploid set of chromosomes) and hence this will increase the likelihood of sperm cooperation to evolve. In addition, haploid gene expression might not be unlimited and hence lower the threshold for sperm cooperation to occur.
Benefits of sperm cooperation include an increase of fertilisation success for both sperm and male in competition with rival sperm or males and therefore, benefits are congruent for both sperm and the male. However, the costs may differ relatively for sperm and for the male: from empirical evidence, it appears that sperm cooperation often involves the loss of fertilisation capability of some sperm (e.g. Moore \& Moore 2002, Moore et al. 2002, Till-Bottraud et al. 2005). In this case, the costs are potentially much higher for sperm than for the male: sperm destroy themselves for the benefit of sibling sperm ( $=$ costs are $100 \%)$, whereas the male loses a certain amount of sperm, yet even if sperm production is costly, the cost to the male is relatively small compared with the cost to the sperm. This discrepancy between the relative cost to sperm and to the male may cause a conflict of interest, since sperm are genetically different from the male.

As outlined above, sperm cooperation will evolve if selective pressures are strong enough, but which are possible selective pressures? Post-copulatory sexual selection including both sperm competition and cryptic female choice may be a potent selective force favouring cooperating sperm and selecting against individually performing sperm. Two theoretical approaches have shown that the evolution of the differentiation of sperm shape and function among sibling sperm in response to post-copulatory sexual selection is possible (Kura \& Nakashima 2000, Holman \& Snook 2006). One model showed that a 'soldier sperm class' may evolve where certain sperm attack rival sperm by potentially destroying themselves (Kura \& Nakashima 2000). Similarly, a subsequent model showed that sperm heteromorphism may evolve if non-fertilising sperm protect fertilising sperm from female spermicide (Holman \& Snook 2006). The next step is to test these ideas empirically.

In the context of post-copulatory sexual selection and of sperm competition in particular, one question that needs to be addressed is: how can it be avoided that sperm of rival males cheat, for example, by joining cooperating sperm of rival males to obtain some fertilisations? There are several possible solutions to this dilemma: (i) sperm cooperation has evolved entirely in response to cryptic female choice and hence the competition with rival males can be ignored and the risk of being exploited is non-existent; (ii) the cooperating units may be formed before ejaculation and are impenetrable to rival sperm when entering the competition; (iii) cooperating units form fast enough and have terminated their formation before the female copulates with the next male or (iv) sperm are capable of recognising sibling sperm, for example, by a green beard effect (Moore et al. 2002), although there is no evidence for the latter so far.

The evolution of sperm cooperation largely depends on the relative importance of diploid and haploid gene expression and in consequence on the role of the 
genetic variation among sibling sperm. In the next two sections, the empirical evidence from the point of view of both the haploid sperm and the diploid male is explored.

\section{Haploid gene expression}

The importance of haploid gene expression for the evolution of sperm shape and function has been explored in theory by Parker \& Begon (1993) who concluded that if haploid genes are expressed they will result in phenotypic variation among sibling sperm. Empirically, however, haploid gene expression and haploid selection have been neglected for several reasons. First, the densely packed nuclear DNA in sperm caused by replacing histones (nuclear proteins typical of the nucleus of normally functional cells) by transition proteins and protamines during spermatogenesis (Dadoune et al. 2004) seems to suggest that gene expression in sperm is suppressed. This appears to be advantageous as the suppression of the haploid genes in sperm would avoid potential conflicts of interest between sibling sperm and between sperm and the diploid male (Parker 1993, Parker \& Begon 1993). Furthermore, it has been argued that sperm lacking DNA partly or entirely (e.g. apyrene sperm in insects) are still perfectly functional (Silberglied et al. 1984), suggesting that the haploid set of genes in a sperm has no effect on sperm function. However, there is growing evidence that haploid gene sets are expressed and under selection, although to a reduced extent compared with diploid gene sets (Joseph \& Kirkpatrick 2004).

A crucial question is how genetically varied sperm of one male are. Without any recombination, maximum variation of sperm genotypes is directly linked to the number of chromosomes of a species and their combinations. However, recombination processes during meiosis increase the genetic variation among sperm considerably and there is some evidence that recombination rate has an influence on the number of sperm produced (Cohen 1967, 1973). This association between recombination rate and sperm number is thought to be based on the fact that sperm haplotypes exhibit varying quality and to make sure that every haplotype is produced at least once, more sperm have to be produced with increasing recombination rate (Manning \& Chamberlain 1994). But how important is this variation in haplotypes among sibling sperm for sperm function?

In mammals, for example, transcription in haploid male germ cells is substantial (Dadoune et al. 2004) and given that after meiosis the haplotype of each sperm is different, sperm may vary in shape and function. However, it is known that cytoplasmic bridges between spermatids during spermiogenesis appear to allow the sharing of haploid gene transcripts and proteins (Dadoune et al. 2004), which would offset the relative importance of haploid gene sets of individual sperm. The fact that transcription is shared during spermiogenesis suggests that at least sperm of one 'generation' are phenotypically identical. Yet, there is increasing evidence that gene expression continues even in mature sperm which may lead to functional differences between sperm. Protein translation has been demonstrated in mature mammalian sperm after ejaculation until the moment of fertilisation (Gur \& Breitbart 2006). In addition, the presence and the considerable variety of mRNA found in bovine sperm suggest that gene expression in mature sperm may play an important role for sperm function (Gilbert et al. 2007), and that genetic differences in haploid sperm may cause functional differences.

Cytoplasmic bridges between haploid spermatids seem to be particularly important, for example, for proteins encoded on $\mathrm{X}$ and $\mathrm{Y}$ chromosomes that are known to determine sperm function (Capel et al. 1993, Hendriksen etal. 1995, Moss et al. 1997, Turner et al. 1998, Westbrook et al. 2000). The genetic difference between $X$ and $Y$ sperm is an extreme example for variation in the haploid gene set between sperm. As mentioned above, the cytoplasmic bridges are likely to buffer most of the phenotypic differences between the $X$ and $Y$ sperm. However, there is some evidence that in humans, $X$ sperm are larger than $Y$ sperm (Cui \& Matthews 1993, Cui 1997). Furthermore, it appears that in bovine sperm, $\mathrm{X}$ and $\mathrm{Y}$ sperm differ in some motility parameters linked to sperm head movements but not in swimming velocity parameters (Penfold et al. 1998). The mechanisms causing these differences between $X$ and $Y$ sperm are not known and need to be investigated further.

\section{Haploid versus diploid gene expression: conflict of interest?}

As a consequence of the evolution of sex, most organisms show a biphasic life cycle where diploid and haploid phases alternate. In plants, the respective duration of the two phases varies considerably among species and it is recognised that the gene expression is distinct in both phases (see Haig \& Wilczek 2006 and references therein). In animals, the diploid phase is often much longer than the haploid one and hence selective pressure during the haploid phase is reduced but not absent (Joseph \& Kirkpatrick 2004). The expression of genes during both phases may lead to a conflict of interest if selection between the phases is disruptive (e.g. Reiss 1987). The potential influence of haploid and diploid gene expression for the evolution of sperm shape and function has been theoretically modelled independently (Parker 1993, Parker \& Begon 1993) but not in combination. It is therefore difficult to make predictions for the strength of a potential conflict of interest between the haploid and diploid phases. Evidence for such a conflict comes from the field of meiotic drive and segregation distortion (see Lyttle 1991, Burt \& Trivers 2006 for reviews) where haploid genes have a strong influence on the genetic 
composition and often on the sex ratio of the sired offspring by manipulating sperm function.

Meiotic drive by manipulation of sperm function can be found in different taxonomic groups. The male drive in the mosquito Aedes aegypti, for example, induces gamete dysfunction through a range of male distorter chromosomes mainly by the breakage of the $\mathrm{X}$ during meiosis, which results in disintegrated sperm organelles (Wood \& Ouda 1987, Wood \& Newton 1991). Similarly, the $X$ chromosome drive in some Drosophila species is based on the degeneration of Y-bearing sperm in males carrying sex-ratio chromosomes (Hauschteck-Jungen \& Maurer 1976). In the fungi Neurospora, spore killers affect half of the meiotic products rendering the spores infertile (Turner \& Perkins 1979, 1991), and in the house mouse Mus musculus, a variant of chromosome 17 called the $t$-haplotype causes segregation distortion where only t-carrying sperm are actually functional whereas +-carrying sperm are immotile (Olds-Clarke \& Peitz 1985, Seitz \& Bennett 1985). The effects of the haplotypes on sperm function may be deleterious to the male as it results in a significant reduction of functional sperm. First, it is costly for males to produce sperm and the production of malfunctional sperm may be a waste of energy (Preston et al. 2001, Wedell et al. 2002). Secondly, the production of malfunctional or variably functional sperm may be disadvantageous in sperm competition if the rival sperm are all fully functional (Calhim et al. 2007). Lyttle (1991), therefore, suggested that segregation distortion mainly occurs in monogamous species. However, neither the house mouse nor the Drosophila species with segregation distortion are necessarily monogamous: most of the species exhibit female multiple mating and sperm competition (Dean et al. 2006, Holman et al. 2008). The quantification of the potential conflict of interest between the sperm and the male caused by diverging selection between the diploid and the haploid life phases might therefore be an interesting topic for future studies.

\section{Empirical evidence for sperm cooperation}

Despite our limited understanding of the theoretical background of the evolution of sperm cooperation, empirical evidence is growing. As outlined earlier, sperm cooperation may affect the phenotypic variation amongst sibling sperm, which may range from (i) almost identical to (ii) strong heteromorphism, and the nature of the cooperative mechanism, which may be (iii) direct or (iv) indirect. Here, the literature for empirical examples of sperm cooperation according to these four different situations is reviewed (see also Table 1).

The idea of differential sperm function for the benefit of the ejaculate as a whole has been triggered by the fact that even in presumably 'homomorphic' ejaculates (i.e. species without any sperm heteromorphism), sibling sperm vary phenotypically and functionally to some degree (Holt \& Van Look 2004; S Immler, unpublished data). However, the empirical evidence for differential sperm function is scarce and often controversial. An experiment in domestic rabbits, Oryctolagus cuniculus, suggested the existence of sperm subpopulations exhibiting differential fertilisation success within the ejaculate of a male (Cohen \& McNaughton 1974; see also Cohen \& Tyler 1980). Female rabbits were mated with one male each, and sperm was recovered from the top end of the oviduct. The sperm obtained from the oviduct was mixed with sperm from an ejaculate obtained directly from a different male and artificially inseminated into a second female. It seemed that an unusually high proportion of the resulting offspring were sired by the male whose sperm were obtained from the oviduct when controlling for the sperm number inseminated from both males. Cohen's result could not be reproduced by subsequent studies (Fischer \& Adams 1981, Foldesy et al. 1984). However, sperm subpopulations have been identified in a different context: Thurston et al. (2001) identified morphologically distinct sperm sub-populations that correlated with fertilisation quality after cryopreservation in boar semen. This result has since been supported by numerous studies of other domestic species. A different approach with a lot of publicity was the 'kamikaze sperm hypothesis' where morphologically 'abnormal' sperm are assumed to have a function in attacking the sperm of rival males by destroying themselves (Baker \& Bellis 1988). However, the 'kamikaze sperm hypothesis' has been shown to be unlikely as several subsequent studies could not find any empirical evidence for it (Harcourt 1991, Moore et al. 1999). Nevertheless, the idea of differential sperm function in species without sperm heteromorphism should be subject to more detailed future studies.

The extreme case of phenotypic and functional variation among sibling sperm is sperm heteromorphism, where a male's ejaculate contains fertile and non-fertile sperm, and which is found in different phyla including plants, arthropods, molluscs and vertebrates (Snook 2005, Till-Bottraud et al. 2005). Sperm heteromorphism may reduce the competition among sibling sperm due to the clear division of labour between fertilising and nonfertilising sperm, which may differ considerably in shape and function. The evolution of sperm heteromorphism in the context of post-copulatory sexual selection has been intensely studied in insects, fish and molluscs and has been reviewed in detail elsewhere (e.g. Silberglied et al. 1984, Swallow \& Wilkinson 2002, Till-Bottraud et al. 2005). In summary, non-fertilising sperm have been thought to (i) be non-adaptive, (ii) provide nutrients for the receiving female or her eggs, (iii) facilitate transport and/or capacitation of fertilising sperm, (iv) play a role in sperm competition by offending rival sperm, or occupy space to inhibit rival sperm from entering the female sperm storage organs, (v) protect fertilising sperm against female spermicide and (vi) influence cryptic female choice (as found in Holman \& 
Table 1 Examples of different forms of sperm cooperation described across taxonomic groups: potential costs and benefits of sperm cooperation are listed as far as they can be estimated.

Type Mechanism $\quad$ Benefits $\quad$ Costs $\quad$ Taxonomic group

Sperm groups

Hooked sperm heads invested by

(1) agglutinative proteins, (2) polysaccharides and (3) mucoproteins; group inside the male

Sperm groups

Adhesion at sperm heads by outer layer of acrosome forming threads of up to 20 sperm long and 5-6 sperm wide; groups inside the male

Sperm group Syncytial sperm bundles with varying sperm number per bundle across species (often 16 or 32 sperm/bundle)

Sperm groups Groups of 5 up to 100 sperm, exact mechanism of attachment unknown electron dense material at ventral region of sperm head and hook shaped sperm head of some species are likely to be involved; group inside male or female

Sperm pairs or groups (1-2) Sperm pairs or groups (4), attached by flattened faces of sperm heads against each other sandwiching electron dense material (periodic acid reactive carbohydrates), attachment loose (1) to very tight $(2,3)$; groups inside male

Sperm pairs Sperm pair formed by septate junctions at heads (left- and right-hand side of head respectively); pair inside male

Sperm pairs Sperm pairs surrounded by capsular sheath (spermatophore), attached by plasma membrane bridge without fusion; pair inside male

Sperm pairs Sperm conjugate by cell fusion in pairs; pair inside male

Sperm pairs and sperm heteromorphism

Fertile sperm form pairs by sandwiching electron-dense material along the acrosome and anterior part of nucleus; non-fertile sperm are produced; pair inside male

Sperm grouping and Apyrene sperm from sheath around sperm heteromor- eupyrene sperm

phism

Sperm heteromorphism Production of fertile (eupyrene) sperm and non-fertile (apyrene) sperm
Potentially increased motility (e.g. Parachauliodes japonicus, Chaliodinae) substance, no sperm damaged at separation

insecta: (1) Corydalidae (Chau-

Reference

lodinae): (2) some Gryllacridae amieson (1987) and Hayashi Ensifera) and Tettigoniidae (e.g. Tettigonia spp.); (3) Acrididae (e.g. Locusta spp., Schistocerca spp.), Cicadidae, Cercopidae, Cicdellidae, Typhlocybidae,

Ulopidae

Not clear

nsecta: Tettigon

Not clear, no sperm

Not clear

damaged at separation

nsecta: Coccidae

Not clear, no sperm
damaged at separation

Sperm groups and individual Sperm damaged by

sperm are motile, but differ in velocity and thrusting force

premature acrosome

Rodentia: Murid dae, Cavidae

1998)

reaction in some

species

Currently investigated

Not clear, sperm not damaged at separation

Insecta: Dytiscidae: (1) Acilius spp., (2) Dytiscus spp.,

(3) Hydraticus spp.

Only pairs are motile, not individual sperm

Not clear

Not clear, sperm not Insecta: Thysanura (e.g. Thermo- Dallai \& Afzelius (1984) damaged at separation bia sp.)

Not clear, sperm not Diplopoda: Colobognatha, Poly- Jamieson (1987)

damaged at separation desmida; Spirostreptida

Spirobolida

(1) Sperm pairs and individual sperm motile, but only pairs reach site of fertilisation; (2) unknown

Paired sperm may swim more vigorously than individual sperm (needs verification), function of non fertile sperm unknown

ertilising sperm need non- Production of nonfertilising sperm for motility fertile sperm

Non-fertile sperm protect/support fertile sperm on their way to ova
Production of non-

(1) Sperm damaged at separation; (2) unknown

\section{Production of non-} fertile sperm

fertile sperm
(1) Mammalia: American marsu- Phillips $(1970,1972)$ and Dallai pials (2) Insecta: Trycholepidion et al. (2001) gertschi

Mollusca: Turritellid snails

Dallai \& Afzelius (1983)

Tubificine worms

Ferraguti et al. (1988), Ferraguti \& Ruprecht (1992) and Boi et al. (2001)

Widespread across taxa (see Silberglied et al. (1984), Swallow references for detailed reviews) \& Wilkinson (2002) and Till-Bottraud et al. (2005) 

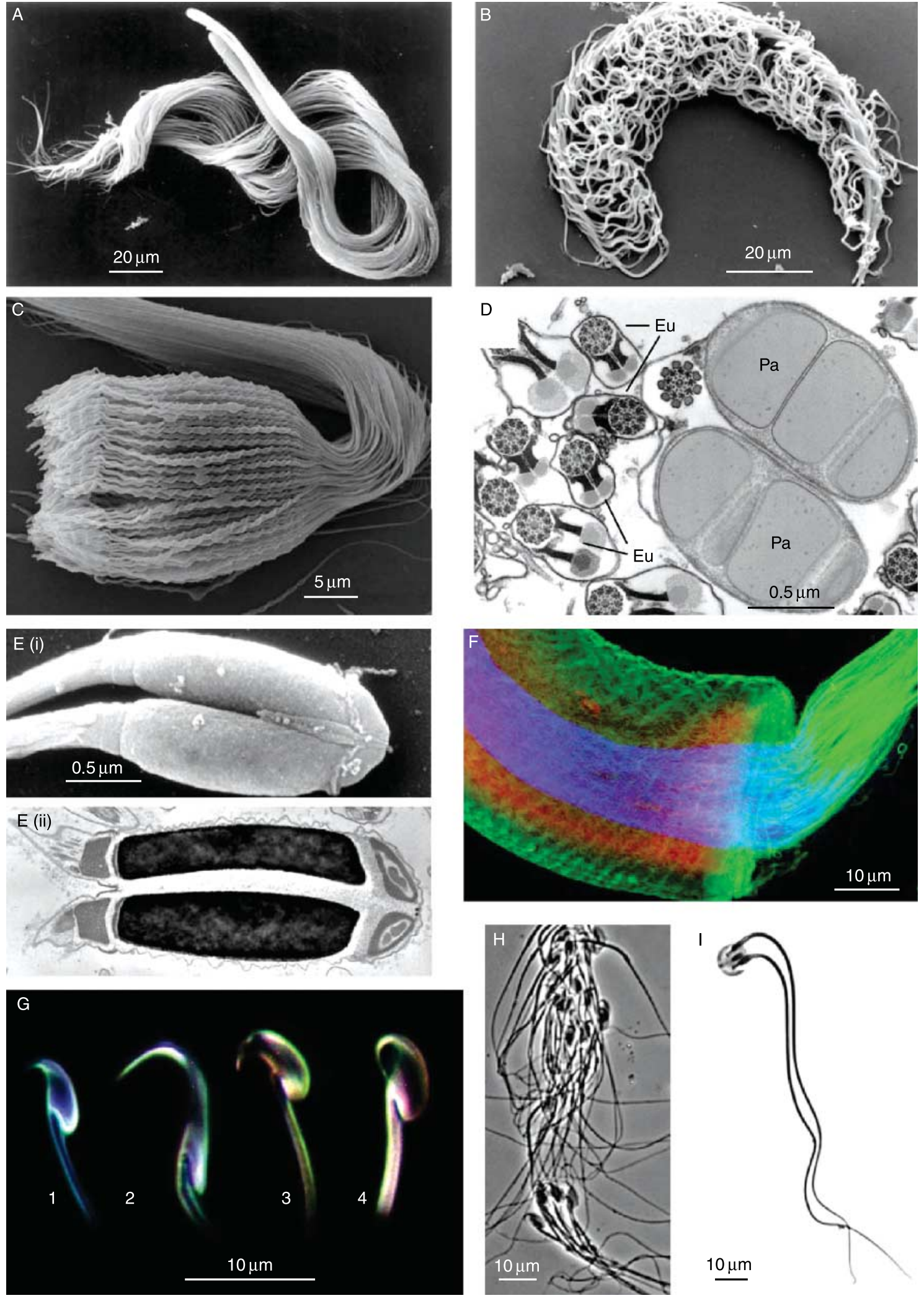
Snook 2006). Whereas sperm heteromorphism is well recognised in insects, it is less well studied in other taxa. In an externally fertilising fish, the marine sculpin Hemilepidotus gilberti, for example, it appears that non-fertile sperm act as an obstacle for sperm of rival males by forming clumps that appear to impede sperm of rival males in reaching the eggs (Hayakawa et al. 2002a, 2002b). In the prosobranch, Goniobasis laqueata eusperm get entangled in the tails of the parasperm so that they cannot disperse and reach the eggs (Woodard 1940). In sperm heteromorphic tubificine worms, two types of sperm aggregate, with the non-fertilising sperm forming a sheath around the fertilising sperm for locomotion (Ferraguti et al. 1988, Ferraguti \& Ruprecht 1992, Boi et al. 2001; Fig. 1F).

It appears that non-fertile sperm have mainly evolved as 'supporters' of fertile sperm to increase the chance of their sibling sperm to fertilise the eggs (Swallow \& Wilkinson 2002, Till-Bottraud et al. 2005). The clear differentiation of sperm according to their roles might reduce the potential conflict of interest and the competition between sibling sperm. Costs to sperm are then theoretically equal to zero as the 'helping' sperm are non-fertile to start with. The costs to the male are linked with the production of non-fertile sperm and since non-fertile sperm might be cheaper than fertile sperm (Holman \& Snook 2006) it might be cheaper overall to produce different types of sperm rather than destructing fully functional sperm for the benefit of sibling sperm. However, the quantification of costs of sperm production including sperm heteromorphism needs future examination.

In contrast to the well-studied phenomenon of sperm heteromorphism, the function of sperm groups in postcopulatory sexual selection has received relatively little attention. This is surprising given the fact that sperm grouping has been described in a wide range of taxonomic groups as diverse as arthropods, chordates and vertebrates (Dujardin 1837, Gray 1928, Phillips 1970, 1972, Dallai \& Afzelius 1984, Jamieson 1987, Moore et al. 2002; Fig. 1A-E). There is some evidence that sperm groups may be advantageous in postcopulatory sexual selection. In the fishfly Parachauliodes japonicus, for example, it has been shown that larger bundles containing more sperm reach the sperm storage organs faster than smaller bundles (Hayashi 1998). Sperm pairing occurs in all American marsupials (except one) but not in Australasian marsupials (Temple-Smith
1987; Fig. 1I). Sperm pair inside the male by aligning their morphologically adapted heads precisely and fusing together (Taggart et al. 1993). Phillips (1970) suggested that the function of sperm pairing in marsupials might offer protection for the acrosome during the passage through the male and female reproductive tracts. However, it has been shown that sperm pairs show increased thrusting force that allows them to reach the site of fertilisation, which is not achieved by individual sperm (Moore \& Taggart 1995, Moore \& Moore 2002). In the European woodmouse Apodemus sylvaticus, sperm form 'trains' by interlocking at their heads and flagella, which swim faster and were found to have increased thrusting force compared with individually moving sperm (Moore et al. 2002; Fig. 1H). The hook-shaped sperm head typical of most murine rodents suggests that sperm cooperation may be more widespread than assumed so far (Immler et al. 2007; Fig. 1G). Sperm groups have also been observed in the Norway rat Rattus norvegicus, where sperm form groups by attaching their heads, which results in increased swimming velocity compared with individual sperm (Immler et al. 2007). By contrast, in the house mouse Mus musculus, the sperm groups are slower than the individual sperm (Immler et al. 2007); however, it might be the combination of swimming velocity and increased thrusting force that results in increased fertilisation success. In the Norway rat and the house mouse, thrusting force in viscous media still needs to be tested. Finally, in monotremes, sperm form groups of up to 100 that move forward nearly three times as fast as individual sperm (Jones et al. 2007).

The costs of sperm grouping are less easy to identify than the costs of sperm heteromorphism as the formation of groups differs among taxonomic groups ranging from the direct attachment of sibling sperm by fusion of the membrane (Phillips 1970, 1972) to the conjugation of sperm by a mucous substance (Jamieson 1987). Where sperm attach to each other, separation prior to fertilisation may damage some sperm, rendering them infertile (Phillips 1970, 1972, Moore et al. 2002). In these cases, costs will be relative to the amount of sperm being damaged during the cooperative process. In the American marsupials, for example, sperm pairing results in the destruction of one sperm during separation, which causes the loss of fertilisation capacity of $50 \%$ of the

Figure 1 (A) Sperm bundle of Galloisiana yuasai (Insecta, Grylloblattodea; photo by R Dallai); (B) spermatodesm of Mantophasma zephyra (Insecta, Mantophasmatodea; photo by R Dallai); (C) sperm bundle of Riftia pachyptila (Polychaeta, Siboglinidae, Vestimentifera; photo by G Melone, M Ferraguti, R Marotta); (D) cross-section through a sperm bundle of Mantispa perla (Insecta, Neuroptera, Planipennia) showing fertilising euspermatozoa (Eu) and non-fertilising paraspermatozoa (Pa), the latter with both large accessory tubules and mitochondrial derivatives (photo by R Dallai); (E) SEM (i) and TEM (ii) of fused sperm pair of Trycholepidion gertschi (Insecta, Zygentoma; photo by R Dallai); (F) confocal microscopy image of a spermatozeugma of Tubifex tubifex (Annelida, Oligochaeta) formed by non-fertilising sperm forming a cylinder around the fertilising sperm (blue, DNA of fertilising sperm; green, tubulin; red, actin; photo by R Marotta, U Fascio, M Ferraguti); (G) variation in apical hook shape and size typical of murine rodents (Rodentia, Muridae; 1, Bunomys fratrorum; 2, Rattus lutreolus; 3, Pseudomys desertor and 4, Apodemus speciosus; photo by S Immler); (H) 'sperm train' of the European woodmouse Apodemus sylvaticus (Rodentia, Muridae; photo by H D M Moore); (I) sperm pair of the American marsupial Monodelphis domestica (Didelphimorphia, Didelphidae; photo by H D M Moore). 
sperm. In species where sperm are not damaged during cooperation, costs will be reduced to the production of glycoproteins and similar sticky substances to glue the sperm together (Dallai \& Afzelius 1984). The relative costs to both the sperm and the male need to be identified and quantified in more detail.

\section{Conclusions and future directions}

The occurrence of sperm cooperation emphasises the potential importance of haploid and diploid gene expression. Most studies of sperm competition have focused on the role of diploid gene expression by investigating adaptations to post-copulatory sexual selection that benefit the male such as sperm number or sperm size (see Birkhead \& Møller 1998 for review). It is important for the future to recognise that sperm produced by one male may not necessarily be considered as working as a unit similar to somatic cells in any of the body's organs (Parker \& Begon 1993). Haploid gene expression is likely to influence the shape and function of sperm, and the evolution of sperm morphology will have to be investigated taking both sides into account and it should be the aim of future studies to quantify the relative importance of haploid and diploid gene expression. This would also involve the investigation of a potential conflict of interest between the haploid and the diploid life cycle, although it will be reduced in most animals due to the short duration of the haploid life cycle.

The study of sperm cooperation and haploid gene expression in the context of post-copulatory sexual selection is still at an early stage and there are many gaps to be filled. The main aims are to identify the costs and benefits of sperm cooperation for both the male and the sperm. Traits that are potentially advantageous in postcopulatory sexual selection have been identified in some cases, such as protection inside the female (L Holman \& RR Snook, unpublished data), 'cheap fillers' to female copulation delay (Cook \& Wedell 1999), inhibitors of rival sperm (Hayakawa et al. 2002a,b), increased swimming velocity and thrusting force of sperm groups (Hayashi 1998, Moore \& Moore 2002, Moore et al. 2002, Immler et al. 2007). In contrast, the costs of sperm cooperation are still poorly understood and should be subject to future studies both from a comparative point of view as well as the variation within species.

\section{Acknowledgements}

I am very grateful to R Dallai, M Ferraguti and H D M Moore for letting me use the beautiful photos for this review. I also thank T R Birkhead, H D M Moore, G A Parker and two anonymous reviewers for useful comments on earlier drafts of the manuscript. S I was funded by a research grant from the Leverhulme Trust. The author declares that there is no conflict of interest that would prejudice the impartiality of this scientific work.

\section{References}

Baker RR \& Bellis MA 1988 'Kamikaze' sperm in mammals? Animal Behaviour 36 936-939.

Birkhead TR \& Møller AP 1998 Sperm Competition and Sexual Selection, London: Academic Press.

Birkhead TR \& Pizzari T 2002 Postcopulatory sexual selection. Nature Reviews 3 262-273.

Boi S, Fascio U \& Ferraguti M 2001 Nuclear fragmentation characterises paraspermiogenesis in Tubifex tubifex. Molecular Reproduction and Development 59 442-450.

Burt A \& Trivers R 2006 Genes in Conflict: the Biology of Selfish Genetic Elements, London: Harvard University Press.

Calhim S, Immler S \& Birkhead TR 2007 Postcopulatory sexual selection is associated with reduced variation in sperm morphology. PLOS ONE 2 e413.

Capel B, Swain A, Nicolis S, Hacker A, Walter M, Koopman P, Goodfellow P \& Lovell-Badge R 1993 Circular transcripts of the testis-determining gene Sry in adult mouse testis. Cell 73 1019-1030.

Cohen J 1967 Correlation between sperm 'redundancy' and chiasma frequency. Nature 215 362-363.

Cohen J 1973 Cross-overs, sperm redundancy and their close association. Heredity 31 408-413.

Cohen J \& McNaughton DC 1974 Spermatozoa: the probable selection of a small population by the genital tract of the female rabbit. Journal of Reproduction and Fertility 39 297-310.

Cohen J \& Tyler KR 1980 Sperm populations in the female genital tract of the rabbit. Journal of Reproduction and Fertility 60 213-218.

Cook PA \& Wedell N 1999 Non-fertile sperm delay female remating. Nature 397486.

Cui KH 1997 Size differences between human X and Y spermatozoa and prefertilization diagnosis. Molecular Human Reproduction 3 61-67.

Cui KH \& Matthews CD 1993 X larger than Y. Nature 366 117-118.

Dadoune J-P, Siffroi J-P \& Alfonsi M-F 2004 Transcription in haploid germ cells. International Review of Cytology 237 1-56.

Dallai R \& Afzelius B 1983 The paired spermatozoa of the marine snail, Turitella communis Lamarck (mollusca, Mesogastropoda). Journal of Ultrastructure Research 85 311-319.

Dallai R \& Afzelius B 1984 Paired spermatozoa in Thermobia (Insecta Thysanura). Journal of Ultrastructure Research 86 67-74.

Dallai R, Lupetti P, Frati F, Nardi F \& Afzelius BA 2001 Binucleate and biflagellate spermatozoa in Tricholepidion gertschi Wygodzynsky (Insecta, Zygentoma). Tissue \& Cell 33 606-613.

Dallai R, Lupetti P, Osella G \& Afzelius BA 2005 Giant sperm cells with accessory macrotubules in a neuropteran insect. Tissue and Cell 37 359-366.

Dean MD, Ardlie KG \& Nachman MW 2006 The frequency of multiple paternity suggests that sperm competition is common in house mice (Mus domesticus). Molecular Ecology 13 4141-4151.

Dujardin F 1837 Sur les zoospermes des mammiferes. Annales des Sciences Naturelles (Zoologie) 2291.

Eberhard WG 1996 Female Control: Sexual Selection by Cryptic Female Choice, Princeton: Princeton University Press.

Ferraguti M \& Ruprecht D 1992 The double sperm line in the tubificid Clitellio arenarius (Annelida Oligochaeta). Bolletino di Zoologia 59 349-362.

Ferraguti M, Bernardini G, Melone G \& Dallai R 1988 Structure and function of the metachronal wave in Tubifex tubifex spermatozeugmata (Annelida Oligochaeta). Journal of Ultrastructure and Molecular Structure Research 99 79-95.

Fischer B \& Adams CE 1981 Fertilization following mixed insemination with 'cervix-selected' and 'unselected' spermatozoa in the rabbit. Journal of Reproduction and Fertility 62 337-343.

Foldesy RG, Bedford JM \& Orgebin-Crist M-C 1984 Fertilizing rabbit spermatozoa are not selected as a special population by the female tract. Journal of Reproduction and Fertility 70 75-82.

Gilbert I, Bissonnette N, Boissonneault G, Vallee M \& Robert C 2007 A molecular analysis of the population of mRNA in bovine spermatozoa. Reproduction 133 1073-1086.

Gray J 1928 Ciliary Movement, Cambridge: University Press.

Gur Y \& Breitbart H 2006 Mammalian sperm translate nuclear-encoded proteins by mitochondrial-type ribosomes. Genes and Development 20 $411-416$

Haig D \& Bergstrom CT 1995 Multiple mating, sperm competition and meiotic drive. Journal of Evolutionary Biology 8 265-282. 
Haig D \& Wilczek A 2006 Sexual conflict and the alternation of haploid and diploid generations. Philosophical Transactions of the Royal Society of London. Series B 361 335-343.

Hamilton WD 1964 The genetical evolution of social behaviour I. Journal of Theoretical Biology 7 1-16.

Harcourt AH 1991 Sperm competition and the evolution of nonfertilizing sperm in mammals. Evolution 45 314-328.

Hauschteck-Jungen E \& Maurer B 1976 Sperm dysfunction in sex ratio males of Drosophila subobscura. Genetica 46 459-477.

Hayakawa Y, Munehara H \& Komaru A 2002a Obstructive role of the dimorphic sperm in a non-copulatory marine sculpin Hemilepidotus gilberti, to prevent other males' eusperm from fertilisation. Environmental Biology of Fishes 64 419-427.

Hayakawa Y, Akiyama R, Munehara H \& Komaru A 2002b Dimorphic sperm influences semen distribution in a non-copulatory sculpin Hemilepidotus gilberti. Environmental Biology of Fishes 65 311-317.

Hayashi F 1998 Sperm co-operation in the fishfly, Parachauliodes japonicus. Functional Ecology 12 347-350.

Hendriksen PJ, Hoogerbrugge JW, Themmen AP, Koken MH, Hoeijmakers JH, Oostra BA, van der Lende T \& Grootegoed JA 1995 Postmeiotic transcription of $\mathrm{X}$ and $\mathrm{Y}$ chromosomal genes during spermatogenesis in the mouse. Developmental Biology 170 730-733.

Holman L \& Snook RR 2006 Spermicide, cryptic female choice and the evolution of sperm form and function. Journal of Evolutionary Biology 19 $1660-1670$.

Holman L, Freckleton RP \& Snook RR 2008 What use is an infertile sperm? A comparative study of sperm-heteromorphic Drosophila. Evolution DOI: 10.1111/j.1558-5646.2007.00280.x.

Holt WV \& Van Look KJW 2004 Concepts in sperm heterogeneity, sperm selection and sperm competition as biological foundations for laboratory tests of semen quality. Reproduction 127 527-535.

Immler S, Moore HDM, Breed WG \& Birkhead TR 2007 By hook or by crook? Morphometry, competition and cooperation in rodent sperm PLoS ONE 2 e170.

Jamieson BGM 1987 The Ultrastructure and Phylogeny of Insect Spermatozoa, Cambridge: University Press.

Jones RC, Dacheux J-L, Nixon B \& Ecroyd HW 2007 Role of the epididymis in sperm competition. Asian Journal of Andrology 9 493-499.

Joseph SB \& Kirkpatrick M 2004 Haploid selection in animals. Trends in Ecology and Evolution 19 592-597.

Kura T \& Nakashima Y 2000 Conditions for the evolution of soldier sperm classes. Evolution 54 72-80.

Lyttle TW 1991 Segregation distorters. Annual Review of Genetics 25 511-557.

Manning JT \& Chamberlain AT 1994 Sib competition and sperm competitiveness: an answer to 'Why so many sperm?' and the recombination/sperm number correlation Proceedings of the Royal Society of London. Series B 256 177-182.

Moore T \& Moore HDM 2002 Marsupial sperm pairing: a case of 'sticky' green beards? Trends in Ecology and Evolution 17113.

Moore HDM \& Taggart DA 1995 Sperm pairing in the opossum increases the efficiency of sperm movement in a viscous environment. Biology of Reproduction 52 947-953.

Moore HDM, Martin M \& Birkhead TR 1999 No evidence for killer sperm or other selective interactions between human spermatozoa in ejaculates of different males in vitro. Proceedings of the Royal Society of London. Series B 266 2343-2350.

Moore HDM, Dvoráková K, Jenkins N \& Breed WG 2002 Exceptional sperm cooperation in the wood mouse. Nature 418 174-177.

Moss SB, VanScoy H \& Gerton GL 1997 Mapping of a haploid transcribed and translated sperm-specific gene to the mouse $\mathrm{X}$ chromosome. Mammalian Genome 8 37-38.

Olds-Clarke P \& Peitz B 1985 Fertility of sperm from $t /+$ mice: evidence that +-bearing sperm are dysfunctional. Genetical Research 47 49-52.

Parker GA 1970 Sperm competition and its evolutionary consequences in the insects. Biological Reviews 45 525-567.

Parker GA 1993 Sperm competition games: sperm size and sperm number under adult control. Proceedings of the Royal Society of London. Series B 253 245-254.

Parker GA 1998 Sperm competition and the evolution of ejaculates: towards a theory base. In Sperm Competition and Sexual Selection, pp 3-54. Eds TR Birkhead \& AP Møller. London: Academic Press.
Parker GA \& Begon ME 1993 Sperm competition games: sperm size and number under gametic control. Proceedings of the Royal Society of London. Series B 253 255-262.

Penfold LM, Holt C, Holt WV, Welch GR, Cran DG \& Johnson LA 1998 Comparative motility of $X$ and $Y$ chromosome-bearing bovine sperm separated on the basis of DNA content by flow sorting. Molecular Reproduction and Development 50 323-327.

Penfold LM, Harnal V, Lynch W, Bird D, Derrickson SR \& Wildt DE 2001 Characterization of Northern pintail (Anas acuta) ejaculate and the effect of sperm preservation on fertility. Reproduction 121 267-275.

Phillips DM 1970 Ultrastructure of spermatozoa of the woolley opossum Caluromys philander. Journal of Ultrastructure Research 33 381-397.

Phillips DM 1972 Comparative analysis of mammalian sperm motility. Journal of Cell Biology 53 561-573.

Preston BT, Stevenson IR, Pemberton JM \& Wilson K 2001 Dominant rams lose out by sperm depletion. Nature $\mathbf{4 0 9} 681-682$.

Reiss MJ 1987 Evolutionary conflict over the control of offspring sex-ratio. Journal of Theoretical Biology 125 25-39.

Seitz AW \& Bennett D 1985 Transmission distortion of $t$ haplotypes is due to interactions between meiotic partners. Nature 313 143-144.

Silberglied RE, Shepherd JG \& Dickinson JL 1984 Eunuchs: the role of apyrene sperm in Lepidoptera. American Naturalist 123 255-265.

Sivinski J 1984 Sperm in competition. In Sperm Competition and the Evolution of Animal Mating Systems, pp 86-115. Ed. RL Smith. London: Academic Press.

Snook RR 2005 Sperm in competition: not playing by the numbers. Trends in Ecology and Evolution 20 46-53.

Swallow JG \& Wilkinson GS 2002 The long and short of sperm polymorphisms in insects. Biological Reviews 77 153-182.

Taggart DA, Johnson JL, O'Brien HP \& Moore HDM 1993 Why do spermatozoa of American marsupials form pairs? A clue from the analysis of sperm-pairing in the epididymis of the grey short-tailed opossum, Monodelphis domestica Anatomical Record 236 465-478.

Temple-Smith PD 1987 Sperm structure and marsupial phylogeny. In Possums and Opossums, pp 273-277. Ed. M Archer. Sydney: Surrey Beatty and Sons.

Thurston LM, Watson PF, Mileham AJ \& Holt W 2001 Morphologically distinct sperm subpopulations defined by Fourier shape descriptors in fresh ejaculates correlate with variation in boar semen quality following cryopreservation. Journal of Andrology 22 382-394.

Till-Bottraud I, Joly D, Lachaise D \& Snook RR 2005 Pollen and sperm heteromorphism: convergence across kingdoms? Journal of Evolutionary Biology 18 1-18.

Turner BC \& Perkins DD 1979 Spore killer, a chromosomal factor in Neurospora that kills meiotic products not containing it. Genetics 93 587-606.

Turner BC \& Perkins DD 1991 Meiotic drive in Neurospora and other fungi. American Naturalist 137 416-429.

Turner RM, Johnson LR, Haig-Ladewig L, Gerton GL \& Moss SB 1998 An $X$-linked gene encodes a major human sperm fibrous sheath protein, hAKAP82. Journal of Biological Chemistry 273 32135-32141.

Wedell N, Gage MJG \& Parker GA 2002 Sperm competition, male prudence and sperm-limited females. Trends in Ecology and Evolution 17 313-320.

Westbrook VA, Diekman AB, Klotz KL, Khole VV, von Kap-Herr C, Golden WL, Eddy RL, Shows TB, Stoler MH, Lee CY et al. 2000 Spermatid-specific expression of the novel X-linked gene product SPAN-X localized to the nucleus of human spermatozoa. Biology of Reproduction 663 469-481.

Wood RJ \& Newton ME 1991 Meiotic drive causing sex ratio distortion in mosquitoes. American Naturalist 137 379-391.

Wood RJ \& Ouda NA 1987 The genetic basis of resistance and sensitivity to the meiotic drive gene D in the mosquito Aedes aegyptii L. Genetica 71 69-79.

Woodard TM 1940 The function of the apyrene spermatozoa of Goniogasis laqueata (Say). Journal of Experimental Zoology 85 103-123.

Received 27 October 2007

First decision 4 December 2007

Accepted 10 January 2008 